REVISTA ECONOMÍA

Vol. 70, N. ${ }^{\circ}$ II2 (noviembre 2018), 7I-86

\title{
EL CRECIMIENTO POBLACIONAL Y LOS BIENES DE PROPIEDAD COMÚN
}

\author{
ROMMEL ALVARADO, MARCO POSSO ZUMÁRRAGA, MARCO POSSO LÓPEZ \\ Universidad Central del Ecuador
}

Recepción de manuscrito: 17 de septiembre de 2018

Aceptación versión final: 26 de octubre de 2018

\begin{abstract}
RESUMEN El presente artículo realiza una actualización crítica de la tragedia de los bienes de propiedad común desde diferentes posturas académicas. Para aquello, se efectúa un análisis de la población mundial, encontrándose que el planeta tiende hacia una sobrepoblación, la cual en el mediano plazo causará la degradación y extinción no solo de este tipo de bienes; sino, de los recursos naturales en general.

palabras Clave Población, externalidades, tragedia de los bienes de propiedad, bienes de propiedad común, políticas públicas.
\end{abstract}

ABSTRACT This article critically updates the tragedy of common property from different academic perspectives. For that, an analysis of the world population is carried out, finding that the planet tends towards an overpopulation, which in the medium term will cause the degradation and extinction not only of this type of common goods; but, of the natural resources in general.

KEYWORDS Population, externalities, tragedy of the common property, common property, public policies.

JALE CODES D7, D70, B52, J11.

\section{INTRODUCCIÓN}

Después del final de la Segunda Guerra Mundial, ocurrida en 1945, el mundo entero empezó a experimentar un nuevo ordenamiento socioeconómico y socioambiental. De esa manera, a los pueblos devastados no les quedó otra alternativa que preocuparse por obtener desde cualquier lugar del planeta ingentes cantidades de recursos naturales y monetarios para empezar su propia reconstrucción. Los afortunados países ganadores se preparaban afanosamente por instrumentalizar geopolíticamente los beneficios de la guerra y así consolidar su hegemonía. En efecto, parte de esta estrategia se consolidó con la intervención del Estado en la economía de esos países, como una forma de regulación.

De esa manera, entre las décadas de los 40 y 70 se experimentó un periodo histórico conocido como la fase de capitalismo regulado. Éste se gestó a través de la aplicación de políticas keynesianas orientadas a: i) la reducción de las fluctuaciones del ciclo económico; ii) alcanzar 
el pleno empleo; iii) la creación de un Estado del bienestar que garantizara la protección y equidad social; iv) la regulación y control de mercados de capital privado y; v) la generación de un relativo equilibrio entre las fuerzas del capital — sectores empresariales - y de los trabajadores - sindicatos- (Solimano 2015, p. 20). Este periodo no tardó en ser cuestionado por «los circuitos conservadores, tanto [económicos], académicos como políticos [...] [que] decidieron revisar nuevamente las premisas conceptuales y prácticas del liberalismo clásico e intentaron adaptarlas a los nuevos desafíos económicos y políticos de aquellos tiempos» (Solimano 2015, p. 21).

En este contexto, existió la imperante búsqueda de crear una nueva forma de organización económica; es decir, implantar una dinámica económica diferente que permita recuperar el poder de la clase capitalista, perdido por dicha regulación. A este proceso se le denominó neoliberalismo «un proyecto [que] a finales de la década de 1970, en Estados Unidos, el porcentaje de la renta nacional en manos del $1 \%$ más rico ascendió hasta alcanzar, a fines del siglo pasado, el 15\%» (Harvey 2007, p. 22). De igual manera, se implementó el libre flujo de los recursos financieros y sociales.

Esta naciente variante del modelo económico capitalista, que en sus inicios prometía el progreso de todas las naciones, con el paso del tiempo mostró su verdadero objetivo hasta convertirse en un instrumento de destrucción; pues sus bases conceptuales y políticas de desarrollo, lejos de impulsar el incremento de la calidad de vida de la población, lo único que hizo fue concentrar la riqueza en pocas manos; así como agravar de manera insostenible los problemas ambientales relacionados principalmente con la contaminación, el cambio climático y el agotamiento de los recursos naturales.

Para entender el origen de dichos problemas ambientales que han venido apareciendo paulatinamente, desde la academia se empiezan a establecer nuevas áreas del saber, tales como: la ecología, la economía ecológica, el ecodesarrollo, la ecología política, entre otras. Todas estas disciplinas, hasta los actuales momentos, han contribuido con importantes explicaciones y reflexiones críticas sobre el manejo y destino que los seres humanos le otorgan al planeta en términos ambientales.

La ecología política, por ejemplo, en su intento por explicar las relaciones socioambientales ligadas con la producción de bienes y servicios, situó en el tapete de la discusión temas muy importantes como la sobrepoblación —en un primer momento estudiado por Thomas Malthus en 1798-, la tragedia de los bienes comunes (Hardin, 1968), los límites del crecimiento económico (Meadows, 1972), entre otros. En síntesis, estos estudios argumentan que el crecimiento acelerado de la población muy pronto alcanzará los límites de crecimiento socioeconómico, y que las soluciones que hoy en día se intentan dar a estas dificultades no se alcanzan con en el desarrollo de la ciencia y la tecnología, sino en el cambio de los valores humanos. Es decir, en términos económicos, la solución a los actuales deterioros ambientales no está en el incremento de la productividad y de las exportaciones.

Por otra parte, otros autores plantean que la solución se encuentra en la equitativa distribución de la riqueza; en este sentido, se plantea que un decrecimiento de la producción o, inclusive, un crecimiento cero, podría ser suficiente para sostener la vida en nuestro planeta (Foster, 2000).

La ecología política busca dar una explicación a través de varias aproximaciones teóricas. 
Figura 1. Crecimiento poblacional versus producción (visión malthusiana)

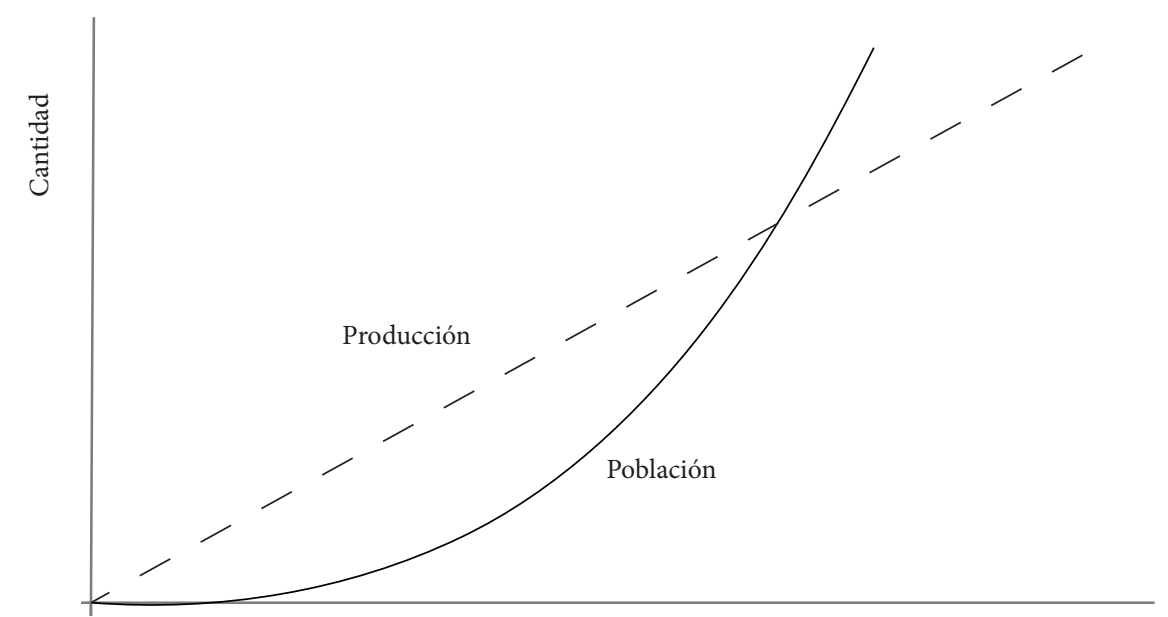

Malthus (1798)

Tiempo

Fuente: Casas (s/f, pág. 200). Elaboración: propia.

En correspondencia con aquello, en el presente trabajo se cuestiona ¿cómo el crecimiento poblacional influye en la degradación de los bienes comunes?, ¿cuáles son los aportes desde distintas perspectivas teóricas sobre la tragedia de los comunes?, ¿existe evidencia de un crecimiento poblacional? Por lo tanto, la estructura del presente artículo es la siguiente: en un primer momento se presenta una revisión sobre la población mundial, luego se hace una caracterización de la evolución que ha tenido el tema de la tragedia de los comunes a través del tiempo.

\section{EL PROBLEMA DE LA SOBREPOBLACIÓN HUMANA}

Uno de los primeros investigadores en abordar los problemas demográficos fue el británico T. Malthus, quien en 1796 publica su célebre Ensayo sobre principio de población. Por aquella época, este reconocido economista develaba que la población mundial tiende a crecer en progresión geométrica, es decir, exponencialmente, mientras que los medios de subsistencia lo hacen en progresión aritmética (ver Figura 1). Por tanto, como todos los recursos materiales que existen en el planeta para satisfacer las necesidades humanas son finitos y escasos, a medida que pasa el tiempo, menos recursos tendrá a su disposición cada individuo para mantener su supervivencia, por consiguiente, el resultado final será el incremento del hambre y la miseria a nivel global (Malthus, 1846).

Esta aseveración puede ocurrir - y de hecho ocurre- en un plano más específico en el ámbito de los alimentos de primera necesidad: mientras la capacidad de producción de alimentos sea mayor que el crecimiento de la población, las necesidades materiales de los seres humanos se pueden satisfacer de manera sustentable (ver Figura 1). Si sucede lo inverso, es decir, 
si la población aumenta más rápido que la cantidad de alimentos disponibles, llegará un momento en el que se generará una insostenibilidad social, donde mucha gente padecerá hambre y morirá por desnutrición.

La originalidad de Malthus radica en que formuló por primera vez una teoría donde se establece una ley general que explica el crecimiento total de la población en relación con la producción de alimentos, destacando los aspectos negativos del crecimiento poblacional y sugiriendo los frenos «preventivos» — retraso de la edad al matrimonio, no mantener relaciones sexuales extramaritales - y los frenos «positivos» - muerte, peste, hambre-, aunque no consideró el mejoramiento de la productividad agrícola por innovación tecnológica y el uso de anticoncepción y, adicionalmente, trató el crecimiento total — crecimiento natural + migración- similar al crecimiento natural - nacimientos - defunciones), por lo cual aseveraba que el crecimiento de la población era atribuible a la natalidad sin considerar el componente migratorio.

La predicción de Malthus hace 220 años sobre la evolución de la población mundial se refleja de manera parcial con las evidencias empíricas disponibles (ver Figura 2). Según la Organización de las Naciones Unidas (ONU, 2017), la población total asciende a los 7632 millones de personas aproximadamente y la tendencia para los próximos 37 años es seguir aumentando hasta llegar a los 10.000 millones en el año 2055, pero con incrementos de menor proporción, debido principalmente a la disminución del promedio de hijos por mujer. De esa forma, a pesar de una tendencia decreciente de la tasa de variación de crecimiento poblacional es todavía es superior al o,50\% hasta el año 2040.

La sobrepoblación humana se debe principalmente a mejores sistemas de salud, incremento de las tasas de natalidad, reducción de las tasas de mortalidad, aumento en las formas de uso de los alimentos, aumento de la esperanza de vida, etc. En este último caso, es claro el cambio estructural que implica el crecimiento más rápido de este indicador ocurrido entre los años de 1945 y 1950. La esperanza de vida, en promedio, pasa de 40 a 49 años, aproximadamente 8 años en un lustro (ver Figura 3). En comparación, en el año 1920 cuando apenas alcanzaban los 34 años. El problema radica en el hecho de que el «exceso» de población obliga a la humanidad a extraer de la naturaleza mayores cantidades de recursos; y como éstos son escasos, su sobreexplotación causa a su vez severos problemas de agotamiento y degradación ambiental porque no alcanzan a renovarse o regenerarse naturalmente y, además, su uso masivo propicia la reproducción intensiva de desechos contaminantes muy peligrosos.

Como consecuencia de esta evidente escasez de recursos y el crecimiento acelerado de la población a nivel planetario, en la actualidad la mayoría de países tienen problemas de pobreza, resquebrajamiento familiar causado por la masiva migración, especialmente en las naciones africanas. ${ }^{1}$ A ello es necesario sumarle el problema que se genera en los países receptores de migrantes, pues muchas veces sus economías no están en capacidad de absorberlos e incorporarlos a la actividad productiva, viéndose obligados a insertarse de manera precaria en el ámbito laboral. Por otro lado, eso genera la implementación de medidas restrictivas contra los migrantes, mismas que por lo general son mal vistas por la comunidad internacional (Guisán y Expósito, 2001).

La perspectiva inmediata promovida por la revolución tecnológica-comercial, así como otros factores señalados, es que la población del planeta seguirá creciendo demográficamente 
Figura 2. Evolución de la población mundial 1950-2050

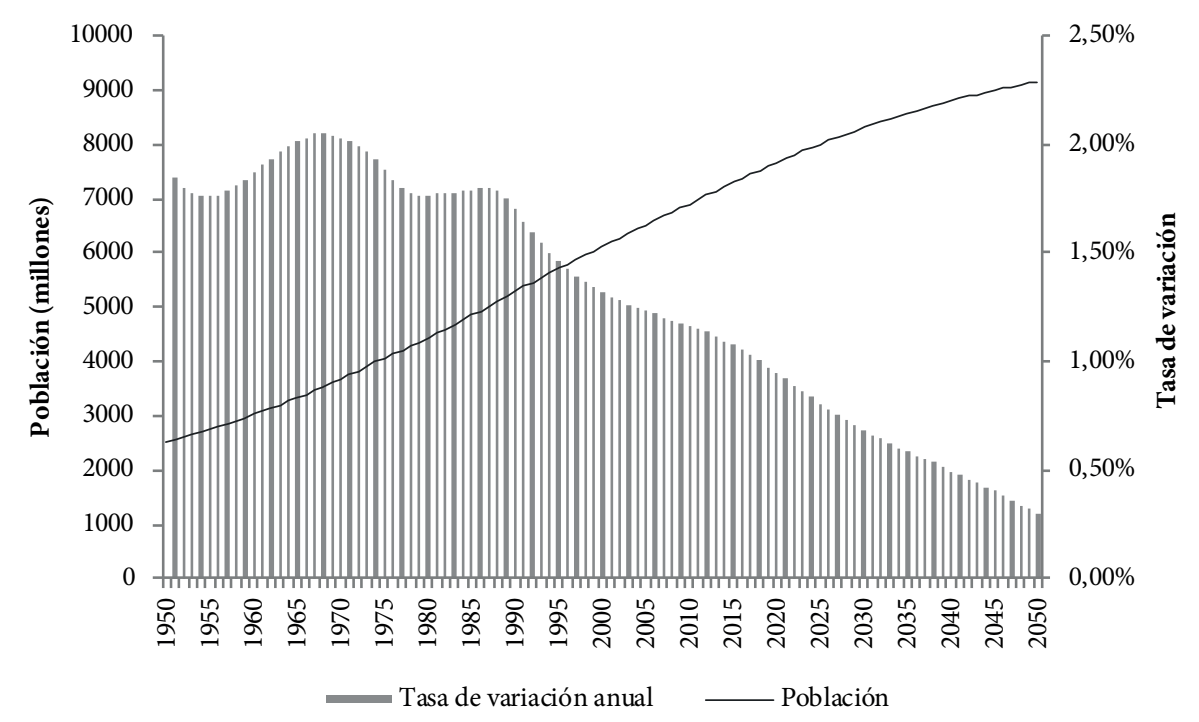

Nota: UN, Population Division. Fuente: Gapminder. Elaboración: propia.

con mayor rapidez y de manera insostenible (Flores, 1976), y la pobreza también continuará extendiéndose, pero esta vez incorporando a otras regiones y continentes, principalmente el continente americano (Flores, 1976) (ver Tabla 1).

Después de Malthus, en nuestra época contemporánea, el ecologista estadounidense Garrett Hardin fue otro investigador que también estudió a profundidad la problemática del exceso de población humana. Siguiendo en la misma línea de Malthus, en sus escritos, Hardin (2009) sostiene que «un mundo con recursos finitos solo puede sostener a una población finita. Por lo tanto, el crecimiento de la población debe ser, al final, igual a cero» (p. 110).

Este crecimiento cero que sugiere Hardin nunca ha ocurrido y tal vez nunca ocurra en la realidad, pues a pesar de los esfuerzos que las familias hacen por controlar la natalidad, en el periodo 2018-2019 la población mundial continuará aumentando a una tasa media de 81,7 millones de habitantes por año (ONU, 2017). Al respecto, lo que se puede intentar hacer es, a lo sumo, calcular un máximo de población permisible en cada nación de tal manera que los recursos naturales alcancen para todos sin el peligro de su agotamiento. No obstante, aquello involucra un costo social muy alto que hasta la actualidad ningún político lo ha analizado y propuesto seriamente, salvo el caso de China, que por razones de exceso de población, ${ }^{2}$ controla estrictamente su natalidad a través de una política rigurosa de planificación familiar. Bajo esta misma lógica, pero con más flexibilidad, en Latinoamérica, los Estados de Cuba y Puerto Rico han sido los únicos que en los últimos años han venido controlando más estrictamente su natalidad, a través de prácticas anticonceptivas y campañas de planificación familiar y esterilización, respectivamente (Bustamante, 2016). 
Entonces, ante esta realidad descrita, surgen varios cuestionamientos, ¿qué se debería hacer ante el crecimiento insostenible de la población mundial? El propio Malthus plantea que hay que limitar voluntariamente el crecimiento poblacional; pero, ¿estaría la población dispuesta a hacerlo? En este caso, la siguiente pregunta sería ¿a qué costo? Éstas son las grandes interrogantes que quedan aún por responder a la población contemporánea si se desea que las generaciones futuras gocen también de un nivel de vida satisfactorio.

\section{TIPOS DE BIENES SEGÚN LA TEORÍA ECONÓMICA}

La ciencia económica clasifica de varias formas los diferentes tipos de bienes que circulan dentro de una economía. Una clasificación la plantea Gregory Mankiw, quien agrupa los bienes basándose en dos categorías: i) exclusión: se puede impedir que las personas usen el bien, y 2) rivalidad en el consumo: el uso del bien por parte de una persona disminuye la capacidad de otra persona para usar el mismo bien. Bajo estas dos categorías, este autor divide los bienes en cuatro grupos: bienes privados, bienes públicos, bienes comunes y bienes reservados (Mankiw, 2012, p. 218).

Antes de entrar a analizar la crítica a la tragedia de los bienes de propiedad común, es conveniente definir primero qué son los bienes de propiedad común y en qué se diferencian de los bienes públicos, ya que en muchas ocasiones el manejo inadecuado de éstos dos términos se ha prestado para la confusión.

Los bienes comunes, desde la perspectiva de Mankiw (2012), son todos aquellos que tienen la cualidad de ser rivales en el consumo, pero no excluyentes. Un ejemplo de este tipo de bienes lo constituyen los peces del océano, pues éstos son rivales en el consumo, es decir, cuando una persona pesca un pez, queda un número menor de peces para que otra persona pesque también; sin embargo, estos peces no son excluyentes, pues al ser el océano considerablemente grande, no se puede impedir que cualquier otro pescador también extraiga libremente los peces del mar. Otros ejemplos de bienes comunes lo conforman los bosques, montañas, animales silvestres, ríos, playas, lagos, medioambiente natural, entre otros. Los bienes públicos en cambio, se caracterizan por no ser ni excluyentes ni rivales en el consumo. Un ejemplo de esta clase de bienes lo representa la alarma de advertencia contra tsunami en una ciudad costera, pues ésta no es excluyente, es decir, cuando suena la alarma, no se puede impedir que cualquier otra persona la oiga también y, además, no es rival en el consumo, pues cuando una persona recibe el beneficio de advertencia de tsunami, no disminuye el derecho del resto de personas de ser advertidas también. Asimismo, son ejemplos de bienes públicos los parques, áreas verdes, desfiles, policía nacional, carreteras, terminales de transporte.

Por otro lado, Hardin (2009, pp. 114-115), sin ser muy riguroso en su definición, considera que un bien de propiedad común es aquel que puede ser usado libremente por cualquier persona que lo desee; en otras palabras, los individuos lo pueden disponer y compartir entre ellos sin restricción alguna. Por ejemplo, los ríos, los océanos, el aire, los bosques, los parques, son considerados por este autor como bienes de propiedad común.

Desde el punto de vista de suministro, generalmente los bienes comunes son generados por la naturaleza, mientras que los bienes públicos son proporcionados por las autoridades de 
Tabla 1. Incrementos de la población mundial por periodos

\begin{tabular}{lcc}
\hline Año & $\begin{array}{c}\text { Población (millones } \\
\text { de habitantes) }\end{array}$ & $\begin{array}{c}\text { Tiempo transcurrido para el incremento de } \\
\text { aproximadamente 1000 millones de habitantes (años) }\end{array}$ \\
\hline 1800 & 1000 & 130 \\
\hline 1930 & 2000 & 30 \\
\hline 1960 & 3023 & 14 \\
\hline 1974 & 3986 & 13 \\
\hline 1987 & 5022 & 12 \\
\hline 1999 & 6035 & 12 \\
\hline 2011 & 6988 & \\
\hline
\end{tabular}

Fuente: Gapminder (2018). Elaboración: propia.

gobierno. Una característica similar que poseen tanto los bienes de propiedad común como los bienes públicos, es que no son excluyentes, es decir, no se puede evitar que las personas usen estos bienes porque están disponibles libremente para todos. Esto se debe principalmente al hecho de que ningún bien común y bien público representa un costo para los individuos que lo utilizan para su propio beneficio, porque dentro del sistema económico no tienen asignado un precio de mercado, como sí lo tienen los otros tipos de bienes, donde los consumidores pagan una determinada cantidad de dinero por cada unidad de producto que demandan.

\section{LA TRAGEDIA DE LOS BIENES DE PROPIEDAD COMÚN}

Desde tiempos muy remotos el ser humano buscó siempre mejorar su calidad de vida. Nuestros ancestros, por ejemplo, constantemente se preocuparon por perfeccionar sus herramientas de recolección y caza para así obtener una mayor cantidad de alimentos. En aquellas épocas, eso era perfectamente factible porque la disponibilidad de recursos naturales no constituía problema alguno, ya que había en cantidades suficientes que alcanzaba para todos sin excepción y, además, la Tierra aún tenía una vasta capacidad para absorber desechos. En el caso de América Latina y el Caribe, hasta antes del descubrimiento se estima que la población indígena era tan solo de 13 millones de personas (Rosenblat, citado en Flores, 1976, p. 122) y los problemas de abastecimiento de subsistencias no existían; sin embargo, en el 2017 la población de toda la región alcanzó los 645,6 millones (ONU, 2017) y las dificultades para proveer de alimentos a todas las familias son más evidentes cada día.

En la actualidad, el panorama no ha cambiado en cuanto al deseo y la necesidad de mejorar la tecnología en aras de obtener un mayor bienestar. No obstante, la capacidad para aumentar el nivel de vida se está reduciendo sustancialmente a medida que pasa el tiempo, porque la naturaleza tiene límites en todas sus dimensiones.

Algunos estudiosos, especialmente los de ideología neoliberal, creen que la solución a los problemas socioeconómicos hoy por hoy se encuentra en el avance de la ciencia y la tecnología. Por ejemplo, se afirma que la explotación intensiva de los mares, la explotación de yacimientos 
petrolíferos y mineros, el desarrollo de nuevas variedades de alimentos, etcétera, resolverán las dificultades de abastecimiento de recursos en la actualidad. Pero esto no resulta ser tan cierto, pues ya existen estudios que demuestran lo contrario: la Organización de las Naciones Unidas para la Alimentación y la Agricultura (FAO, 2018) sostiene que las poblaciones de peces marinos que son biológicamente sostenibles se han reducido del 90\% en 1974 al 66,9\% en el 2015, situación que es corroborada por Worm et al. (2006) al afirmar que en el año 2050 los recursos pesqueros del mar se agotarán si se sigue extrayendo a tasas tan elevadas como las de ahora; Meadows (citado en Gudynas, 2012, pp. 25-26) encontró, en cambio, que en el año 2070 se alcanzarían los límites del crecimiento económico, donde lo más probable que ocurra es un descenso incontrolable de la población y la capacidad industrial.

Frente a esta serie de controversias, Garrett Hardin decidió analizar la escasez de recursos delimitando su estudio únicamente en los bienes que son de propiedad común. Durante sus investigaciones encontró que:

[L]os problemas globales de agotamiento de los recursos naturales de libre disponibilidad que están enfrentando las ciudades son causados por el exceso de población y; por lo tanto, dicho exceso no puede solucionarse de manera técnica, sino, cambiando los valores humanos relacionados principalmente con la ética y la moral (Hardin, 2009, pp. 108 - 109).

Desde una perspectiva económica, Mankiw (2012) afirma que si un bien carece de precio de mercado, como los bienes comunes, por ejemplo, surge un problema en la distribución de ese bien, pues los productores del sector privado no encuentran incentivos para ofrecerles a los consumidores las cantidades apropiadas que ellos demandan en un momento dado. Bajo estas circunstancias, «las políticas públicas emitidas por el gobierno podrían remediar estas fallas del mercado y mejorar la distribución de los bienes y el bienestar económico de la población» (p. 218). Este escenario de dificultad y preocupación mundial motivó a Hardin en la década de 1960 a proponer a la comunidad científica el debate de una nueva concepción filosófica, conocida con el nombre de «la tragedia de los bienes de propiedad común».

Para este autor, los bienes que son de propiedad de todos (comunes), tales como los árboles de un bosque o los peces de un río, por ejemplo, al inicio pueden tener la capacidad suficiente para cubrir las necesidades materiales de una determinada población; pero, a medida que esta población crece, dicho río o dicho bosque va perdiendo su capacidad natural de reproducción y abastecimiento hasta agotarse o extinguirse - provocando inclusive muertes por hambre o escasez-; y es ahí cuando ocurre entonces la catástrofe social o, en otras palabras, es ahí cuando ocurre la «tragedia para los bienes comunitarios que pertenecen a toda la sociedad» (Hardin, 2009, p. 114).

La tragedia de los bienes de propiedad común ocurre porque nuestras actividades diarias continuamente están generando un fenómeno muy particular que en el campo de la economía se conoce como externalidades. En reflexiones de Mankiw (2012), a través del equilibrio entre la oferta y la demanda el mercado puede suministrar eficientemente, por ejemplo, la cantidad adecuada de gasolina que necesitan las personas. No obstante, este mismo mercado no puede impedir que dicho combustible contamine un bien común como lo es el aire, ya que los vendedores y los compradores de gasolina no toman en cuenta los efectos externos que causan sus decisiones. A esto último se le denomina externalidades. 
Figura 3. Evolución promedio de la esperanza de vida a nivel mundial 1765-2050

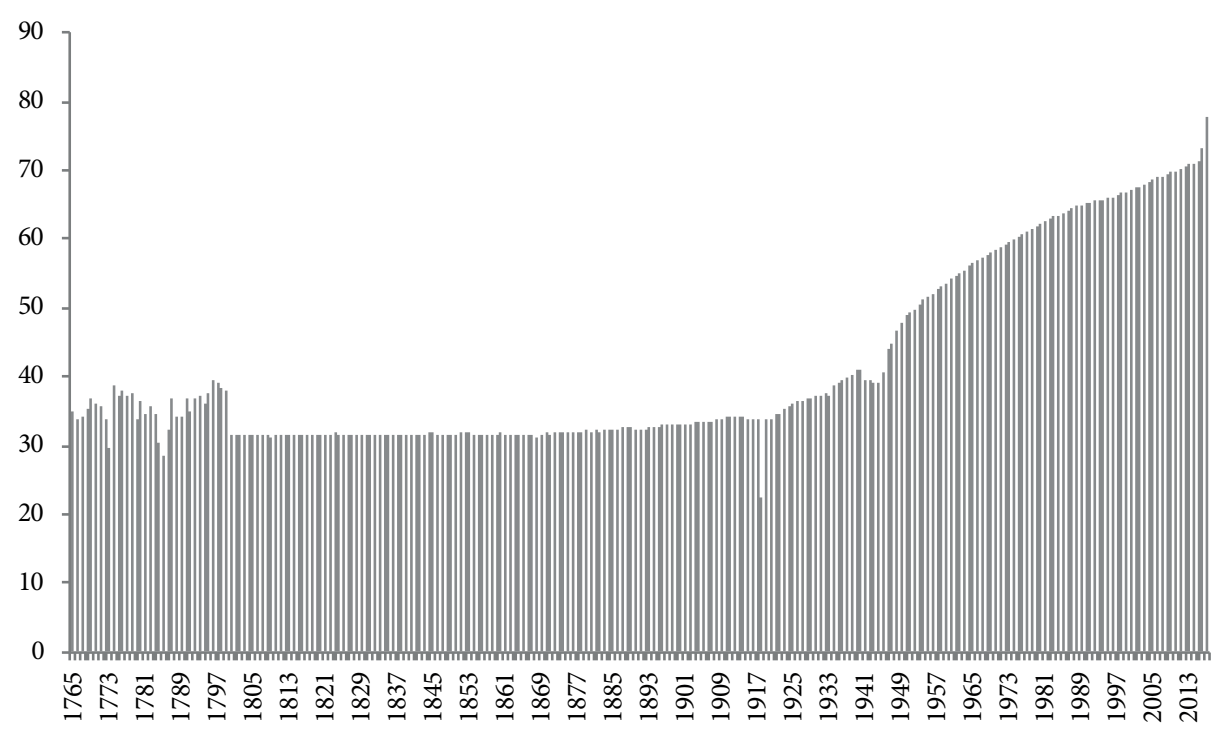

Nota: UN, Population Division. Fuente: Gapminder. Elaboración: propia.

Una externalidad resulta ser, por lo tanto, el efecto que generan las actividades de una persona sobre el bienestar de otras terceras personas. Se denomina externalidad positiva cuando el efecto o impacto que reciben esas terceras personas es beneficioso para ellas, por ejemplo, «reforestar un bosque; caso contrario, si el efecto o impacto es perjudicial se denomina externalidad negativa, ejemplo: contaminar un río» (Mankiw, 2012, pp. 196, 219). Entre estas externalidades puede observarse el aumento de las emisiones de $\mathrm{CO}_{2}$ desde la década de 1960 (ver Figura 4).

La tragedia de los bienes comunes se enmarca dentro de las externalidades negativas y son consecuencia de las fallas del mercado, pues éste a través de las fuerzas de la oferta y la demanda no puede impedir que los perjuicios que generan las actividades realizadas por un determinado grupo de personas, afecte negativamente a otro grupo de personas. Se produce básicamente en todos los llamados bienes comunes que tienen valor para la sociedad, pero que no tienen asignado un precio en el mercado.

Para evitar que ocurra la tragedia de los bienes comunes que se acaba de describir, se han propuesto algunas alternativas, siendo la más relevante la racionalización del uso éstos a través de su regulación, privatización o manejo estatal.

\section{POLÍTICAS PÚBLICAS PARA EVITAR LA TRAGEDIA DE LOS BIENES DE PROPIEDAD COMÚN}

El tema de la tragedia de los bienes de propiedad común, analizado y publicado por primera vez en 1968 por Hardin, abrió un amplio espacio de debate y reflexión, no solo en el ámbito 
académico, sino también en el ámbito político, económico y religioso. Su aparición se tornó relevante y experimentó un gran auge posteriormente porque empezaron a emerger con fuerza problemas sociales muy sensibles, tales como la escasez de alimentos, la contaminación ambiental, las guerras entre países por la disputa de recursos naturales, entre otros.

En respuesta a esta problemática, las autoridades de la academia empezaron a conformar comisiones de profesionales especializados para estudiar más a profundidad, y desde diferentes visiones, el tema de los bienes comunes y de los recursos naturales en general. Algunos de los trabajos más destacados son de Dennis Meadows (1992) sobre los límites del crecimiento, además de otros realizados en colaboración (Meadows, Meadows y Randers, 1994); del profesor universitario Worm et al. (2006) sobre el agotamiento de los recursos marinos. Y al ser la tragedia de los bienes comunes una externalidad negativa producida por las fallas del mercado, Mankiw (2012) sostiene que:

[...] [E]s el gobierno quien debe tomar medidas para mejorar los resultados del mercado, pues solo de esta manera se crearán las condiciones necesarias para evitar que la degradación de este tipo de bienes continúe. Esto está sustentado desde el punto de vista económico, ya que mediante el equilibrio entre la oferta y la demanda el mercado solo es bueno para distribuir eficientemente los recursos escasos; pero, no es bueno para impedir que las empresas y los hogares contaminen, y es ahí cuando el Estado debe intervenir (p. 196).

Por otro lado, Ostrom (2014) confirma que autoridades gubernamentales de varios países empezaron a crear y fortalecer instituciones para ejercer una mejor gobernanza y llevar un control más detallado y eficiente de los bienes de propiedad común.

Bajo esta misma preocupación, han surgido nuevos planteamientos como alternativas sostenibles de desarrollo, especialmente para aquellos países que basan sus economías en la extracción intensiva de sus recursos naturales. Así, aparece en Ecuador y en Bolivia la tesis del Buen Vivir, la misma que plantea lograr un mejor bienestar para la población, pero en armonía con la naturaleza (Constitución de la República del Ecuador, 2008). Por otro lado, también surge la tesis del decrecimiento económico mundial, la cual recomienda reducir en todo el planeta la producción de bienes hasta una tasa óptima, tal que permita alcanzar una sociedad equilibrada en base a una redistribución equitativa de la riqueza (Latouche, 2009, pp. 15, 45).

En lo relacionado a la pesca y la acuicultura, el sistema de las Naciones Unidas alineado al Objetivo 14 de Desarrollo Sostenible y en concordancia con los principios de igualdad y no discriminación, ha ratificado su esfuerzo para conservar los recursos marinos y así apoyar el desarrollo sostenible de los pescadores, sus familias y sus comunidades. Para lograr aquello, se ha comprometido a colaborar para la consecución de la meta de «sobrepesca cero» establecida en la Agenda 2030, ejecutando varias políticas entre las que se destacan la sensibilización de la población, conferencias a nivel mundial para la concienciación de este problema, declaratoria del Día Internacional de la Lucha contra la Pesca Ilegal no declarada y no reglamentada, declaratoria del Año Internacional de la Pesca y la Acuicultura Artesanales, ejecución de reuniones bienales del Comité de Pesca de la FAO (FAO, 2018, pp. 85-86).

A nivel internacional, es relevante evidenciar el problema de la destrucción de los glaciares en Chile por parte de las empresas mineras. Para salvaguardar estas masas de hielo, diversas 


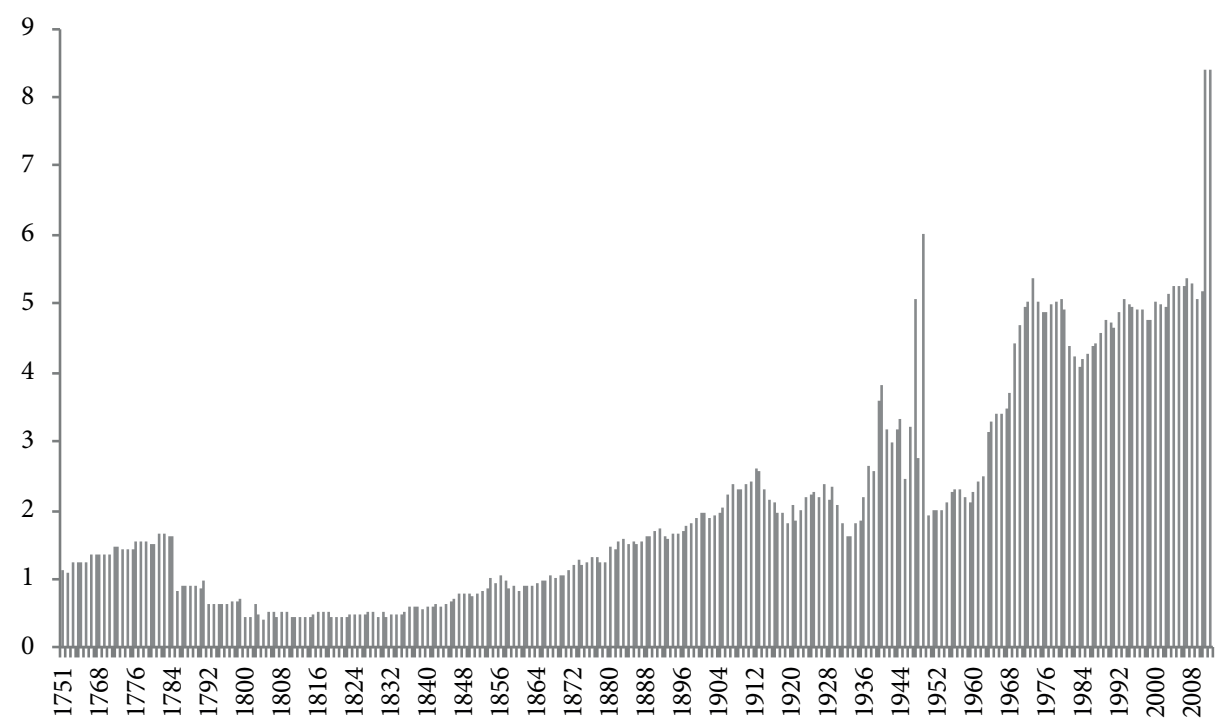

Nota: promedio de emisiones de $\mathrm{CO}_{2}$ en toneladas métricas por persona durante el año en cuestión, calculado a partir de la desviación del $\mathrm{CO}_{2}$ total con la población total de los países. Fuente: Gapminder. Elaboración: propia.

organizaciones ecologistas presentaron en el 2006 al gobierno un proyecto de Ley para la Protección de Glaciares, con el fin de considerarlos jurídicamente objetos de seguridad estratégica para el mantenimiento de los ecosistemas, el abastecimiento de las poblaciones humanas y las actividades productivas. A pesar de esta importante iniciativa, el gobierno aún no ha patrocinado el proyecto (Fundación Heinrich Böll Stiftung Cono Sur, 2013).

Es necesario recalcar, en definitiva, que los esfuerzos por lograr el desarrollo sustentable sin entrar en la tragedia de los bienes comunes se han realizado con ímpetu solo en el ámbito de la utilización racional de la naturaleza y de la conservación del medioambiente. A pesar de estar conscientes que a medida que aumenta la población también es necesario aumentar la extracción de recursos naturales para construir más escuelas, más hospitales, más autobuses, más computadoras, más teléfonos celulares, etcétera, muy poco se ha hecho para moderar la natalidad en aras de no sobreexplotar los recursos naturales y así permitir a la naturaleza su autoregeneración, salvo el caso de los programas gubernamentales de planificación familiar que son importantes, pero insuficientes.

\section{CRÍTICA A LA TRAGEDIA DE LOS BIENES DE PROPIEDAD COMÚN}

Las ideas planteadas por Hardin con relación a la tragedia de los bienes de propiedad común, 
no han estado exentas de diferentes debates académicos, detractores y defensores; algunos de los trabajos de mayor resonancia son los de Laval y Dardot (2016), Svampa (2013), Aguilera (2012), Worm (2006), McCay y Jentoft (1998), Feeny, Berkes, McCay y Acheson (1996) y Casas (s. f.). Estas discusiones han abonado las diversas reflexiones en torno a cómo entender la problemática de la escasez de este tipo de bienes pero - sobre todo- a replantearse qué hacer. En este sentido, es importante destacar que no todas estas críticas señalan directamente a la sobrepoblación humana como la principal causante del problema de la tragedia de los bienes de propiedad común. A saber:

- Los economistas Feeny, Berkes, McCay y Acheson (1996) indican que los análisis de Hardin sobre la tragedia o destrucción de los bienes comunes son incompletos y limitados, porque consideran que la propiedad común es lo mismo que el acceso abierto - acceso gratuito para todos-, lo cual genera confusiones. Además, no toma en cuenta otras categorías como propiedad comunal y propiedad estatal.

- El economista ecológico Aguilera (2012, pp. 51-52) afirma que las ideas de Hardin sobre la tragedia de los comunes son erróneas y no tienen nada que ver con el deseo de proteger este tipo de bienes, sino, con el deseo de posicionar una ideología que busca la privatización y la intervención estatal de los recursos de propiedad común, para así solucionar los problemas ambientales y poblacionales que le preocupaban en ese momento.

- Las antropólogas McCay y Jentoft (1998) revelan que la tragedia de los bienes de propiedad común no está relacionada directamente con el aumento de la población como lo plantea Hardin, sino con las fallas que genera el mercado al no poder distribuir equitativamente la riqueza social, lo cual obliga a los pobres a intensificar indiscriminadamente la extracción de recursos naturales para no morirse de hambre. La Comisión Económica para América Latina y el Caribe (CEPAL) (2016) respalda esta afirmación, pues sus estudios demuestran, por ejemplo, que en el año 2014 el 10\% más rico de la población latinoamericana poseía el 71\% de la riqueza de la región.

- El ecologista Worm et al. (2006) sostiene que el agotamiento de los bienes comunes como los peces del mar, por ejemplo- se debe a la exagerada sobreexplotación que hacemos de ellos, situación que al final de cuentas termina perjudicando a toda la naturaleza en su conjunto - escasez de bienes, contaminación ambiental, etcétera-. Aquello lo corrobora la FAO (2018, p. 42) al afirmar que los grupos de peces del mar biológicamente sostenibles disminuyeron del $90 \%$ en 1974 al 66,9\% en el 2015 .

- El agrónomo Casas (s. f.) manifiesta en sus investigaciones que la degradación de los suelos causada irresponsablemente por los seres humanos reduce la disponibilidad de todos los recursos comunes y no comunes que existen en el planeta. Para reforzar esta afirmación, la FAO (s. f.) indica que a nivel mundial de 5 a 7 millones de hectáreas de tierra aptas para la agricultura se pierden cada año por la erosión y degradación.

- La socióloga Svampa (2013) considera que el nuevo ordenamiento socioeconómico caracterizado por la extracción y exportación de bienes naturales a gran escala, como los metales y el petróleo, por ejemplo, es el que origina la escasez y pérdida de los recursos naturales a través del deterioro ambiental. Al respecto, la Organización de Países Exportadores de Petróleo (OPEP) (2018) sustenta esta afirmación al señalar que en el 2017 la producción promedio de petróleo alcanzó los 96,4 millones de barriles diarios; de su parte, el Carbon Dioxide Information 
Analysis Center (CDIAC, 2018) indica que en el 2014 las emisiones de CO2 en el aire provenientes de combustibles fósiles ascendieron a 9855 millones de toneladas métricas de carbono, cifra nada alentadora si queremos mitigar los severos problemas de calentamiento global.

- Para Laval y Dardot (2016) la noción de lo común se conjuga con lo colectivo, lo público y lo privado. De esta manera, ante el advenimiento del neoliberalismo, existe una privatización hostil que transforma lo que para Solimano (2015) antes era impensable. En este sentido, la eficiencia de lo común se plantea como una forma de contrarrestar la idea de que ante algo escaso, que ese algo sea comunitario es una tragedia. No obstante, lo común supera a la idea de un bien, se refiere a la relación entre distintos actores sobre algo. Este proceso puede resumirse como una gestión. Por lo tanto, se analiza la gestión de lo común y lo público aparece como lo común, con una lógica que se resignifica en el Estado, a partir de una dinámica histórica que se cristaliza en el Estado. Así, lo común atravesado por la institucionalidad.

Como se puede apreciar, existen varias críticas a las ideas de la tragedia de los bienes de propiedad común planteadas por Hardin. En la actualidad, el centro del debate gira en torno a la extracción intensiva de los recursos naturales como los hidrocarburos y los metales, especialmente en los países subdesarrollados como los sudamericanos.

\section{CONCLUSIONES}

El tamaño de la población mundial en los actuales momentos es de aproximadamente de 7632 millones de personas, y para el periodo 2018-2019 continuará creciendo a un ritmo promedio de 81,7 millones de habitantes por año. Si no se cambian los hábitos de consumo, si no se mejoran las prácticas de producción de alimentos y/o no se moderan las tasas de crecimiento poblacional, la vida en este planeta se volverá insostenible en el mediano plazo.

Frente a los problemas ambientales y escasez de bienes comunes y no comunes, los avances tecnológicos no parecen ser una solución; por el contrario, los agrava aún más porque se demanda de la naturaleza mayores cantidades de todo tipo de recursos.

La mayoría de los bienes de propiedad común han entrado a una crisis de existencia; es decir, a un agotamiento acelerado que conducirá a una catástrofe social (tragedia), como es el caso de los recursos del mar, que está previsto que en el año 2050 su disponibilidad disminuya drásticamente si se los sigue sobreexplotando. Sin embargo, de acuerdo a las críticas surgidas de diversos sectores, no está claramente definido si esto se debe a la sobrepoblación mundial o a la sobreexplotación global de los recursos naturales ocasionada por el consumismo que promueve el sistema capitalista.

Las futuras generaciones tendrán que enfrentar serios problemas de subsistencia y dificultades ambientales si se considera erróneamente que los recursos naturales y la capacidad del planeta para recibir desechos contaminantes son infinitos.

La tragedia de los bienes de propiedad común planteada por Hardin constituye una externalidad negativa producida por las fallas del mercado de bienes. Dentro del ámbito científico, esta tesis ha tenido más críticas que aceptaciones y sus detractores han surgido de diferentes campos del conocimiento, tales como ecología, economía, agronomía, antropología, sociología, etcétera. 
Para la conservación de los bienes de propiedad común, la sociedad mundial parece necesario adoptar un cambio urgente frente a los problemas de sobrepoblación, consumismo, el agotamiento de los recursos naturales y la contaminación ambiental. Es muy probable que en el mediano plazo, por ejemplo, bienes comunes como los peces del mar o los árboles de los bosques entren en un proceso de escasez acelerada.

\section{NOTAS}

1 Guisán y Expósito (2001, pp. 4-10) afirman que los problemas de sobrepoblación en África se podrían solucionar elevando el nivel de educación de la gente, aumentando la producción industrial y permitiendo el desarrollo económico de esas naciones. Es decir, el aumento de los años de escolaridad de los habitantes contribuye a alcanzar altos niveles de producto interno bruto (PIB), disminuye sustancialmente las tasas de fertilidad y, por ende, modera las excesivas tasas de crecimiento de la población, lo cual evidentemente permitirá luchar contra la pobreza y el estancamiento económico de esta región.

2 China tiene una población de 1353 millones de habitantes aproximadamente (oNU, 2018). Debido a esta cantidad de gente tan elevada, este país asiático controla mediante leyes la natalidad permitiendo tener a cada familia únicamente dos hijos, con el fin de contrarrestar sus problemas socioeconómicos (El Financiero, 2018).

\section{REFERENCIAS}

Aguilera, F. (2012). Hardin, Ostrom y los recursos de propiedad común: un desencuentro inevitable y necesario. Documentación Social, (165), 49-66. Recuperado de https://nanopdf.com/download/ hardin-ostrom-y-los-recursos-de-propiedad-comun-un_pdf

Bustamante Olguín, F. (2016). Nicolás Sánchez Albornoz (2014). Historia mínima de la población de América Latina. Cuatrocientos siglos de historia, desde los tiempos precolombinos hasta el (no tan lejano) año 2025. Si Somos Americanos, 16(1), 213-217. Recuperado de https://scielo.conicyt. $\mathrm{cl} / \mathrm{pdf} / \mathrm{ssa} / \mathrm{v16n}$ //artog.pdf

Cae la natalidad en China pese a alivio de política familiar. (2018, enero 19). El Financiero. Recuperado de http://www.elfinanciero.com.mx/mundo/cae-la-natalidad-en-china-pese-a-alivio-de-poli tica-familiar

Carbon Dioxide Information Analysis Center (CDIAC). (2018). Global Fossil-Fuel CO2 Emissions. Recuperado de http://cdiac.ess-dive.lbl.gov/trends/emis/tre_glob_2014.html

Casas, R. (s. f.). La conservación de los suelos y la sustentabilidad de los sistemas agrícolas. Universidad Nacional de la Plata. Recuperado de http://sedici.unlp.edu.ar/bitstream/handle/10915/30748/ Documento_completo.pdf?sequence=1

Comisión Económica para América Latina y el Caribe (CEPAL). (2016). América Latina y el Caribe es la región más desigual del mundo. ¿Cómo solucionarlo? cepal. Recuperado de https://www.cepal. org/fr/node/ 35842

Constitución de la República del Ecuador. (2008). Asamblea Nacional de la República del Ecuador. (s. d.). Feeny, D., Berkes, F. McCay, B. y Acheson, J. (1996). La tragedia de los comunes: 22 años más tarde. El Jarocho Verde, (8), 20-29. Recuperado de http://www.lavida.org.mx/sites/default/ files/201308/8.03\%2OLA\%2OTRAGEDIA\%2ODE\%2OLOS\%2OCOMUNES.pdf 
Flores, E. (1976). La población de América Latina desde los tiempos precolombinos hasta el año 2000. Revista Geográfica de América Central, 1(4), 121-125. Recuperado de http://www.revistas.una.ac.cr/ index.php/geografica/article/view/3144/3003

Foster, J. B. (2000). Marx's Ecology: materialism and nature. New York, USA: Monthly Review Press.

Fundación Heinrich Böll Stiftung Cono Sur. (2013). Glaciares y minería: continúa la destrucción de los glaciares. Recuperado de https://cl.boell.org/sites/default/files/o6_glaciares_7_final.pdf

Gapminder. (2018). Evolución de la población mundial. GaPMINDER (DATA). Recuperado de https://www. gapminder.org/data/

Gudynas, E. (2012). Debates sobre el desarrollo y sus alternativas en América Latina: una breve guía heterodoxa. En M. Lang y D. Mokrani (Ed.), Más allá del desarrollo (pp. 21-53). Quito, Ecuador: Fundación Rosa Luxemburg/Abya Yala.

Guisán, M. y Expósito, P. (2001). Educación, desarrollo y emigración en África. Nuevas políticas de cooperación europea e internacional. Estudios Económicos de Desarrollo Internacional, 1(2), 1-13. Recuperado de https://core.ac.uk/download/pdf/6369087.pdf

Hardin, G. (2009). La tragedia de los bienes de propiedad común. En C. Crawford (Ed.), Derecho ambiental y justicia social (pp. 105-133). Bogotá, Colombia: Siglo del Hombre Editores.

Harvey, D. (2007). Breve historia del neoliberalismo. Madrid, España: Akal.

Latouche, S. (2009). Pequeño tratado del decrecimiento sereno. Barcelona, España: Icaria Editorial s. A.

Laval, C. y Dardot, P. (2016). Común. Ensayo sobre la revolución del siglo xxi. Barcelona, España: Gedisa.

Malthus, T. (1846). Ensayo sobre el principio de la población. Recuperado de http://books.google.es/ books? $\mathrm{id}=8 \mathrm{TdB} 7 \mathrm{Y}_{3} \mathrm{XYiAC} \& \mathrm{dq}=$ ensayo $\% 20$ sobre\%2oel\%2oprincipio\%2ode\%2ola\%2opoblaci $\%$ $\mathrm{C}_{3} \% \mathrm{~B}_{3}$ \&pg $=\mathrm{PR}_{3} \# \mathrm{v}=$ onepage $\& \mathrm{q} \& \mathrm{f}=$ false

Mankiw, G. (2012). Principios de Economía. Recuperado de http://www.jaimedv.com/eco/1c1-micro/mankiw-principios-eco-ed6.pdf

McCay, B., y Jentoft, S. (1998). ¿Market or community failure? Critical perspectives on common property research. Human Organization, 57(1), 21-29. Recuperado de http://www.atmosp.physics.utoronto. ca/people/lev/ESSgc/mccayJCommunityfailure.pdf

Meadows, D. (1972). Los límites del crecimiento. México DF, México: FCE.

Meadows, D., Meadows, D. y Randers, J. (1994). Más allá de los límites del crecimiento. Madrid, España: El País s. A./Aguilar s. A.

Organización de las Naciones Unidas (ONU). (2017). World population prospects: The 2017 Revision. Recuperado de https://esa.un.org/unpd/wpp/Download/Standard/Population/

Organización de las Naciones Unidas (ONU). (2018). Social indicators: population. Recuperado de http:// unstats.un.org/unsd/demographic/products/socind/default.htm

Organización de las Naciones Unidas para la Alimentación y la Agricultura (FAO). (2018). El estado mundial de la pesca y la acuicultura 2018. Cumplir los objetivos de desarrollo sostenible. Recuperado de http://www.fao.org/3/I9540ES/i9540es.pdf

Organización de las Naciones Unidas para la Alimentación y la Agricultura (FAO). (s. f.). Restoring the land. Recuperado de http://www.fao.org/docrep/u8480e/U848oEoD.HTM

Organización de Países Exportadores de Petróleo (OPEP). (2018). Market indicators as at end: June 2018. Recuperado de https://www.opec.org/opec_web/static_files_project/images/content/data_graphs/MIo62018.pdf 
Ostrom, E. (2014). El gobierno de los bienes comunes desde el punto de vista de la ciudadanía. Ciencias, (111-112), 144-153. Recuperado de http://www.revistaciencias.unam.mx/es/161-revistas/revistaciencias-111-112/1405-el-gobierno-de-los-bienes-comunes-desde-el-punto-de-vista-de-laciudadan $\% \mathrm{C}_{3} \% \mathrm{ADa} \cdot \mathrm{html}$

Solimano, A. (2015). Elites económicas, crisis y el capitalismo del siglo xxi. La alternativa de la democracia económica. Santiago de Chile, Chile: Fondo de Cultura Económica Chile s. A.

Svampa, M. (2013, diciembre). Consenso de los commodities, un debate actual. En J. Ponce (Presidencia), Desarrollo y Ambiente. Simposio llevado a cabo en el vi Congreso Iberoamericano de Desarrollo y Ambiente. Quito, Ecuador.

Worm, B., Barbier, E., Beaumont, N., Duffy, J., Folke C., Halpern, B. y Watson, R. (2006). Impacts of biodiversity loss on ocean ecosystem services. Science, 314, 787-79o. Recuperado de http://palumbi. stanford.edu/manuscripts/impacts\%20of\%2obiodiversity\%2oloss\%2oon\%2oocean\%2oecosystem\%2oservices.pdf 